\title{
Polymorphisms near Interleukin 28B Gene Are Not Associated with Hepatitis B Virus Clearance, Hepatitis B e Antigen Clearance and Hepatocellular Carcinoma Occurrence
}

\author{
Dong Hyeon Lee ${ }^{a} \quad Y_{\text {ri Cho }}{ }^{\mathrm{a}} \quad$ Ji Yeon Seo ${ }^{\mathrm{a}}$ Jung Hee Kwon ${ }^{\mathrm{a}}$ Eun Ju Cho ${ }^{\mathrm{a}}$ \\ Eun Sun Jang ${ }^{a}$ Min-Sun Kwak ${ }^{a}$ Jae Youn Cheong ${ }^{c}$ Sung Won Cho ${ }^{c}$ \\ Jeong-Hoon Lee ${ }^{a}$ Su Jong $\mathrm{Yu}^{\mathrm{a}}$ Jung-Hwan Yoon ${ }^{\mathrm{a}}$ Hyo-Suk Lee $^{\mathrm{a}}$ \\ Chung Yong Kim ${ }^{a}$ Hyoung Doo Shin ${ }^{b}$ Yoon Jun Kim ${ }^{a}$

\begin{abstract}
a Department of Internal Medicine and Liver Research Institute, Seoul National University College of Medicine, Seoul National University Hospital, and ${ }^{b}$ Department of Life Science, Sogang University, Seoul, and ${ }^{\mathrm{C} D e p a r t m e n t}$ of Gastroenterology, Ajou University School of Medicine, Suwon, Republic of Korea
\end{abstract}

\section{Key Words}

IL28B - Single nucleotide polymorphism • Haplotype ·

Hepatitis B virus $\cdot$ Hepatocellular carcinoma

\begin{abstract}
Background: Polymorphisms near the IL28B gene have been proposed to be strongly associated with treatment response and the rate of spontaneous clearance of hepatitis $C$ virus infection, and treatment response of hepatitis B virus (HBV) infection. In this study, we aimed to determine whether these polymorphisms could affect natural courses of HBV infection. Methods: Genetic variations were identified through direct DNA sequencing using TaqMan assay in 1,439 patients with past or present HBV infection. Subjects included 404 spontaneously recovered patients, 313 chronic hepatitis B (CHB) patients, 305 liver cirrhosis (LC) patients and 417 hepatocellular carcinoma (HCC) patients. Three polymorphisms near the IL28B gene, rs8099917T $>G$, rs12979860C $>T$ and rs12980275A>G, were identified. Associations between these polymorphisms and HBV clearance, hepatitis B e anti-
\end{abstract}

gen ( $\mathrm{HBeAg}$ ) clearance as well as HCC occurrence among patients were analyzed using logistic regression analyses adjusted for age and gender. Results: There were no significant associations between these polymorphisms and the HBV clearance both in CHB and LC groups. Similarly, these polymorphisms showed no significant associations with $\mathrm{HBeAg}$ clearance and the occurrence of HCC either. Discussion: No significant association was identified between polymorphisms near the IL28B gene and the natural courses of chronic HBV infection, including the HBV clearance and HCC occurrence.

Copyright $\odot 2013$ S. Karger AG, Basel

\section{Introduction}

Infection with hepatitis B virus (HBV) is one of the great global public health problems. The clinical outcome of HBV infection varies, and ranges from spontaneous recovery to chronic carriers (CC) or even death from hepatocellular carcinoma (HCC). Although a vaccine

\section{KARGER}

Fax +4161306 1234

E-Mail karger@karger.ch

www.karger.com
(C) 2013 S. Karger AG, Basel

0300-5526/13/0562-0084\$38.00/0

Accessible online at:

www.karger.com/int
Prof. Yoon Jun Kim

Seoul National University Hospital

101 Daehang-no, Jongno-gu

Seoul 110-744 (Korea)

Tel. +82 22072 3081, E-Mail yoonjun@snu.ac.kr 
against $\mathrm{HBV}$ is available, more than 350 million people worldwide are still in a CC state of HBV [1]. Chronic HBV infection is a major risk factor for several liver diseases, such as chronic hepatitis B (CHB), liver cirrhosis (LC) and HCC [2], which was the twelfth most common cancer and the eighth leading cause of cancer-related mortality in the USA in 2011 [3].

The molecular mechanisms that induce the different outcomes of HBV infection still remain undetermined. However, some family and twin studies show that host genetic factors are the probable cause influencing the outcome of HBV infection [4, 5]. Indeed, our previous studies have demonstrated that genetic variations in histone deacetylase 10, Fas/Fas ligand, transforming growth factor- $\alpha / \beta 1$, interleukin (IL) 10 , monocyte chemotactic protein-1, cyclin D2, DNA methyltransferase 1, insulin-like growth factor 2 and secreted phosphoprotein-1 are related to HBV clearance [6-8], HCC progression [9-12], or both [13, 14]. In spite of these results, associations of HBV-related liver diseases with other host genetic diversities still need further investigation.

The IL28B gene, which forms a cytokine gene cluster on chromosome 19q13, encodes for interferon-lambda (IFN- $\lambda$ ) 3. IFN- $\lambda$ activates a cascade through the JAK/ STAT pathway, which induces IFN-stimulated genes [15, 16]. This cytokine has been certified as an important modulator of the immune response to hepatitis $C$ virus (HCV). Genetic polymorphisms near the IL28B gene are associated with the response to pegylated interferon (PEG-IFN)- $\alpha$ and ribavirin therapy for chronic hepatitis $\mathrm{C}$ [17]. Furthermore, the same polymorphisms are associated with spontaneous clearance of HCV [18]. The exact biologic mechanism or pathway of this phenomenon remains unclear, but the influence of single nucleotide polymorphisms (SNPs) near the IL28B gene might not be limited in chronic HCV clearance. It is known that IFN$\lambda$ exhibits antitumoral activities in several experimental studies in cell lines and animal models [19-22]. In addition, higher spontaneous recovery rates of $\mathrm{HCV}$ infection in patients with favorable genotypes might lead to lower risk of HCC development. Several studies have already shown that the polymorphisms near the IL28B gene are associated with HCC occurrence in patients with chronic HCV infection [23].

Although the mechanism by which IL28B influences outcome of $\mathrm{HCV}$ infection remains elusive, it is likely that the relationship is not specific to $\mathrm{HCV}$ infection. IFN- $\lambda$ has been shown previously to be active against several other viruses, including HBV [24], and HBV is also an IFN- $\alpha$-responsive chronic viral illness. Indeed, the rela- tionship between genetic variation of the IL28B gene and serologic response to PEG-IFN in patients with hepatitis $\mathrm{B}$ e antigen ( $\mathrm{HBeAg}$ )-positive $\mathrm{CHB}$ has been recently determined [25]. However, the association of polymorphisms near the IL28B gene with natural courses in patients with chronic HBV infection, such as spontaneous recovery, HBeAg clearance or HCC occurrence, has not been previously characterized. Accordingly, this study was conducted to determine whether polymorphisms near the IL28B gene could affect HBV clearance and HCC occurrence in chronic HBV-infected patients.

\section{Materials and Methods}

\section{Study Patients}

A total of 1,439 individuals having either past or present evidence of HBV infection were recruited from patients enrolled in the outpatient clinic of the Liver Unit and the Center for Health Promotion at Seoul National University Hospital and Ajou University Medical Center. Diagnoses of chronic carriers and spontaneously recovered individuals were established by repeated seropositivity for hepatitis B surface antigen (HBsAg; Enzygnost1 HBsAg 5.0; Dade Behring, Marburg, Germany) over a 6-month period, and for both anti-HBs (antibody to hepatitis B surface antigen; Enzygnost Anti-HBs II; Dade Behring) and anti-HBc (antibody to hepatitis B core antigen; AB-Corek; DiaSorin, Saluggia, Italy) of the IgG type without HBsAg, respectively. The chronic carrier group was assessed further for disease progression to cirrhosis or HCC. All patients in the chronic carrier group had undergone regular medical follow-ups and had been evaluated with serum alpha-fetoprotein level, abdominal ultrasonography and/ or a 4-phase spiral liver CT scans more than twice a year to detect early stages of HCC. Dynamic contrast-enhanced abdominal MRI, bone scan, chest CT, brain MRI, brain CT, hepatic angiography or PET scan was also carried out in some patients based on the clinical decision.

Diagnosis of HCC was based on image findings of nodules larger than $1 \mathrm{~cm}$ showing intense arterial uptake followed by washout of contrast in the venous-delayed phases in a 4-phase multidetector CT scan or dynamic contrast-enhanced MRI and/ or biopsy [26]. Cirrhosis of the liver, on the other hand, was diagnosed by biopsy or based on the clinical evidence of portal hypertension such as visible collateral vessels on the abdominal wall, esophageal varices on esophagogastroscopy, palpable splenomegaly and sonographically definite findings of cirrhotic liver or ascites. The age of onset of HCC was determined according to the date of initial diagnosis.

Exclusion criteria for the study patients were the following: (i) testing positive for anti-HBs but not for anti-HBc; (ii) testing positive for anti-HCV or anti-HIV (GENEDIA ${ }^{\circledR}$; Greencross Life Science Corp., Yongin-shi, Korea, $\mathrm{HCV}^{\circledR}$ 3.2; Dong-A Pharmaceutical Co., Seoul, Korea); (iii) average alcohol consumption of $\geq 10$ g/day or an average number of $\geq 1$ cigarette pack/s smoked daily assessed through individual interviews, and (iv) incurrence of other types of liver diseases such as autoimmune hepatitis, toxic hepatitis, hemochromatosis, Wilson's disease, nonalcoholic ste- 
atohepatitis, primary biliary cirrhosis or Budd-Chiari syndrome. None of the patients had a previous history of immunosuppressant or anti-viral treatment, including interferon and/or nucleos(t)ide analogues. Finally, informed written consent was obtained from the patients prior to conducting the study, and ethical approval was obtained from the Institutional Review Board for Human Research at Seoul National University Hospital and Ajou University Medical Center.

\section{Genotyping of IL28B Gene Polymorphisms}

Using the Wizard genomic DNA purification kit (Promega, Madison, Wisc., USA), genomic DNA was extracted from patients' peripheral blood samples. In addition, SNP genotyping was performed using the TaqMan [27] assay in the ABI prism 7900HT sequence detection system (Applied Biosystems, Foster City, Calif., USA). Genotyping quality control was performed in $10 \%$ of the samples by duplicate checking (rate of concordance in duplicates $=100 \%)$. The $I L 28 B$ gene polymorphisms, rs8099917, rs12979860 and rs12980275, were genotyped as described previously [28]. In more detail, Assays-On-Demand probe was used for rs8099917 (Applied Biosystems ref. C_11710096_10), and probes of rs12979860 and rs12980275 were custom designed. For rs12979860, primer sequences were: forward TGTACTGAACCAGGGAGCTC and reverse GCGCGGAGTGCAATTCAAC, and probe sequences were: Vic-TGGTTCGCGCCTTC and Fam-TGGTTCACGCCTTC. For rs12980275, primer sequences were: forward GTGCTGAGAGAAGTCAAATTCC and reverse CCGCTACCCGGCAAATATT, and probe sequences were: Vic-AGACACGTCTGTTTCTA and Fam-ACACGTCCGTTTCTA.

Statistical Analyses

To determine the association of rs8099917, rs12979860 and rs12980275 with HBV clearance as well as HCC occurrence, the odds ratio (95\% confidence interval) was calculated using logistic analysis adjusted for age (continuous value) and gender (male $=0$, female $=1$ ) as covariates to eliminate or reduce any confounds that might influence the findings. Data was managed and analyzed using the Statistical Analysis System (SAS) version 9.1 (SAS Inc., Cary, N.C., USA). Using the PHASE algorithm, version 2.0 [29], haplotypes were then inferred from the genotyped SNPs. Lewontin's $D^{\prime}\left(\left|D^{\prime}\right|\right)$ and the linkage disequilibrium (LD) coefficient $\mathrm{r}^{2}$ were then examined using the Haploview algorithm [30] to measure the LD between all pairs of biallelic loci.

\section{Results}

\section{Polymorphisms near the IL28B Gene}

By direct sequencing, three SNPs were identified near the region of the IL28B gene on chromosome 19q13.13. They were $\mathrm{rs} 8099917 \mathrm{~T}>\mathrm{G}, \quad \mathrm{rs} 12979860 \mathrm{C}>\mathrm{T}$ and rs12980275A $>$ G (fig. 1a). Minor allele frequencies of these SNPs were 0.053, 0.060 and 0.066 among Korean subjects (table 2). Genotype distributions in all loci were in Hardy-Weinberg equilibrium $(\mathrm{p}>0.05)$. Five haplotypes were inferred from three polymorphisms, and the

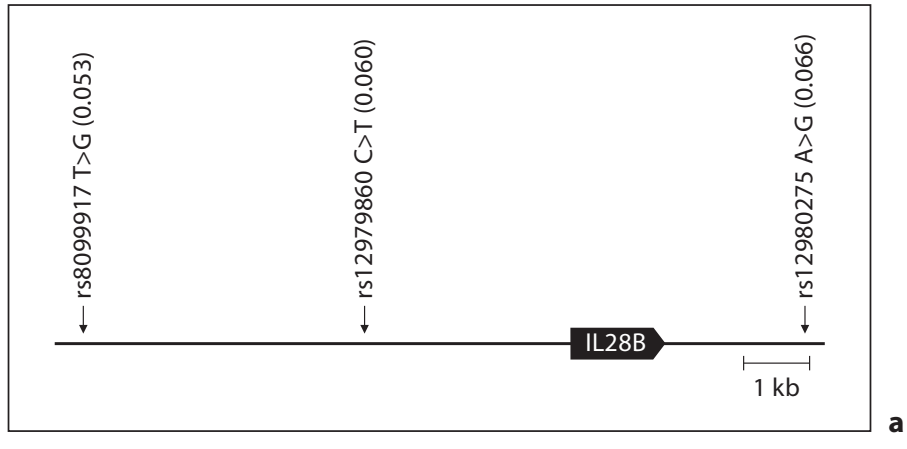

\begin{tabular}{|lllll|}
\hline Hap. & rs8099917 & rs12979860 & rs12980275 & Freq. \\
\hline ht1 & T & C & A & 0.933 \\
ht2 & G & T & G & 0.050 \\
ht3 & T & C & G & 0.008 \\
ht4 & T & T & G & 0.007 \\
ht5 & G & T & A & 0.002 \\
\hline
\end{tabular}

\begin{tabular}{|lllll|}
\hline \multicolumn{2}{l}{ SNPs } & $\left|D^{\prime}\right|$ & & \\
\cline { 3 - 5 } & & rs8099917 & rs12979860 & rs12980275 \\
\hline & rs8099917 & - & 1.000 & 0.956 \\
$r^{2}$ & $r s 12979860$ & 0.874 & - & 0.961 \\
& rs12980275 & 0.715 & 0.827 & - \\
\hline
\end{tabular}

Fig. 1. Physical map, haplotypes and linkage disequilibrium of IL28B gene polymorphisms. a Location of IL28B gene polymorphisms on chromosome 19q13.13. The black block represents the IL28B gene. The frequency in parentheses was based on the genotyping data $(\mathrm{n}=1,439)$. b Haplotypes of rs8099917, rs12979860 and rs12980275. c Linkage disequilibrium coefficient $\left(\left|D^{\prime}\right|\right.$ and $\left.\mathrm{r}^{2}\right)$ among the three SNPs.

most common haplotype was T-C-A (fig. 1b). The frequency of T-C-A was 0.933, while those of other haplotypes were below 0.050. The SNPs rs8099917 and rs12979860 were in strong linkage disequilibrium $\left(\mathrm{r}^{2}=\right.$ 0.874 ; fig. 1c). The linkage disequilibrium between rs8099917 or rs12979860 and rs12980275 was smaller $\left(r^{2}=0.715\right.$ and $\left.r^{2}=0.827\right)$.

\section{Clinical Profiles of the Study Patients}

A total of 1,439 Korean subjects with past or present evidence of $\mathrm{HBV}$ infection were enrolled in the study and classified into 2 subgroups: (1) 404 spontaneously recovered subjects as controls, and (2) 1,035 chronic HBV-infected patients (table 1). Chronic HBV-infected patients were composed of $313 \mathrm{CH}$ subjects, $305 \mathrm{LC}$ subjects and 
Table 1. Clinical profiles of the study patients

\begin{tabular}{|c|c|c|c|c|}
\hline \multirow[t]{2}{*}{ Clinical profile } & \multirow{2}{*}{$\begin{array}{l}\text { Spontaneously } \\
\text { recovered }\end{array}$} & \multicolumn{3}{|l|}{ Chronic carrier } \\
\hline & & $\begin{array}{l}\text { hepatocellular } \\
\text { carcinoma }\end{array}$ & $\begin{array}{l}\text { liver } \\
\text { cirrhosis }\end{array}$ & $\begin{array}{l}\text { chronic } \\
\text { hepatitis }\end{array}$ \\
\hline Patients, $\mathrm{n}$ & 404 & 417 & 305 & 313 \\
\hline Mean age (range), years & $53.1(28-81)$ & $57.5(25-82)$ & $50.8(22-90)$ & $44.4(18-79)$ \\
\hline Gender (male/female) & $272 / 132$ & $279 / 48$ & $231 / 74$ & $238 / 75$ \\
\hline $\mathrm{HBeAg}$-positive rate, $\%$ & 0 & 25.7 & 29.7 & 37.1 \\
\hline $\mathrm{HBeAb}$-positive rate, $\%$ & 37.7 & 65.8 & 50.2 & 44.9 \\
\hline HBsAg-positive rate, \% & 0 & 100 & 100 & 100 \\
\hline HBsAb-positive rate, \% & 100 & 0 & 0 & 0 \\
\hline
\end{tabular}

Table 2. Genotypes and minor allele frequencies of SNPs in the IL28B gene among Korean subjects $(\mathrm{n}=1,439)$

\begin{tabular}{|c|c|c|c|c|c|c|c|c|}
\hline rs & $\mathrm{Chr}$ & Coordinate $^{1}$ & $\begin{array}{l}\text { Location rela- } \\
\text { tive to } I L 28 B\end{array}$ & Alleles & $\begin{array}{l}\text { Genotype } \\
\text { (samples, n) }\end{array}$ & MAF & $\begin{array}{l}\text { Hetero- } \\
\text { zygosity }\end{array}$ & $\mathrm{HWE}^{2}$ \\
\hline rs8099917 & 19 & 39743165 & Promoter & $\mathrm{T}>\mathrm{G}$ & $\begin{array}{l}\mathrm{TT}(1,253) \\
\mathrm{TG}(137) \\
\mathrm{GG}(6)\end{array}$ & 0.053 & 0.101 & 0.963 \\
\hline rs12979860 & 19 & 39738787 & Promoter & $\mathrm{C}>\mathrm{T}$ & $\begin{array}{l}\mathrm{CC}(1,242) \\
\mathrm{CT}(155) \\
\mathrm{TT}(6)\end{array}$ & 0.060 & 0.112 & 0.770 \\
\hline rs12980275 & 19 & 39731783 & $3^{\prime}$ downstream & $A>G$ & $\begin{array}{l}\text { AA }(1,234) \\
\text { AG }(167) \\
\text { GG }(9)\end{array}$ & 0.066 & 0.123 & 0.669 \\
\hline
\end{tabular}

${ }^{1}$ Human genome build 37.

${ }^{2} \mathrm{p}$ values of deviation from Hardy-Weinberg equilibrium among a spontaneously recovered group.

417 HCC subjects. Subjects with more progressive disease tended to be older and had a higher male to female ratio, as well as lower positive rate of $\mathrm{HBeAg}$.

\section{Association Analysis of Polymorphisms near the}

IL28B Gene with Spontaneous Clearance of HBV

We analyzed the association of polymorphisms near the IL28B gene with the rate of spontaneous clearance of HBV among Korean subjects with $\mathrm{CH}$ (table 3). Polymorphism rs8099917T $>$ G had no significant association with the clearance of HBV $(\mathrm{OR}=1.02, \mathrm{p}=0.90$ in a codominant model; $\mathrm{OR}=1.01, \mathrm{p}=0.97$ in a dominant model; $\mathrm{OR}=1.58$, $\mathrm{p}=0.68$ in a recessive model). Similarly, neither did $\mathrm{rs} 12979860 \mathrm{C}>\mathrm{T}(\mathrm{OR}=1.03, \mathrm{p}=0.89$ in a codominant model; $\mathrm{OR}=1.01, \mathrm{p}=0.94$ in a dominant model; $\mathrm{OR}=1.57, \mathrm{p}=$ 0.68 in a recessive model), nor $r s 12980275 \mathrm{~A}>\mathrm{G}(\mathrm{OR}=1.09$, $\mathrm{p}=0.60$ in a co-dominant model; $\mathrm{OR}=1.06, \mathrm{p}=0.75$ in a dominant model; $\mathrm{OR}=2.86, \mathrm{p}=0.32$ in a recessive model).
Association Analysis of Polymorphisms near the IL28B Gene with Risk of HCC Occurrence

There were no statistically significant associations between polymorphisms near the IL28B gene and the occurrence of LC and HCC. Polymorphisms rs8099917T $>\mathrm{G}$ $(\mathrm{OR}=0.82, \mathrm{p}=0.37$ in a codominant model; $\mathrm{OR}=0.86$, $\mathrm{p}=0.51$ in a dominant model), rs12979860C $>\mathrm{T}(\mathrm{OR}=$ $0.80, \mathrm{p}=0.31$ in a codominant model; $\mathrm{OR}=0.84, \mathrm{p}=0.43$ in a dominant model) and $\operatorname{rs} 12980275 \mathrm{~A}>\mathrm{G}(\mathrm{OR}=0.72$, $\mathrm{p}=0.11$ in a codominant model; $\mathrm{OR}=0.73, \mathrm{p}=0.16$ in a dominant model; $\mathrm{OR}=0.16, \mathrm{p}=0.10$ in a recessive model) did not show statistically significant association with the occurrence of HCC in $\mathrm{CH}$ and LC groups. Similarly, rs8099917T $>\mathrm{G}(\mathrm{OR}=0.77, \mathrm{p}=0.31$ in a codominant model; $\mathrm{OR}=0.84, \mathrm{p}=0.52$ in a dominant model), rs $12979860 \mathrm{C}>\mathrm{T}(\mathrm{OR}=0.75, \mathrm{p}=0.22$ in a codominant model; $\mathrm{OR}=0.80, \mathrm{p}=0.38$ in a dominant model), and $\mathrm{rs} 12980275 \mathrm{~A}>\mathrm{G}(\mathrm{OR}=0.66, \mathrm{p}=0.07$ in a codominant 
Table 3. Association analysis of the $I L 28 B$ gene polymorphisms with risk of liver disease in Korean subjects $(\mathrm{n}=1,439)$

\begin{tabular}{|c|c|c|c|c|c|c|c|c|c|}
\hline \multirow[t]{2}{*}{ Test group } & \multirow[t]{2}{*}{ rs } & \multicolumn{2}{|c|}{ Minor allele frequency } & \multicolumn{2}{|l|}{ Codominant } & \multicolumn{2}{|l|}{ Dominant } & \multicolumn{2}{|l|}{ Recessive } \\
\hline & & case & control & OR $(95 \% \mathrm{CI})$ & $\mathrm{p}$ & OR (95\% CI) & $\mathrm{p}$ & OR (95\% CI) & $\mathrm{p}$ \\
\hline HBV infection & rs8099917 & 0.054 & 0.051 & $1.02(0.71-1.48)$ & 0.90 & $1.01(0.68-1.49)$ & 0.97 & $1.58(0.18-13.64)$ & 0.68 \\
\hline $\mathrm{HBV}(\mathrm{n}=1,035)$ vs. & rs12979860 & 0.060 & 0.057 & $1.03(0.72-1.46)$ & 0.89 & $1.01(0.70-1.47)$ & 0.94 & $1.57(0.18-13.49)$ & 0.68 \\
\hline $\mathrm{SR}(\mathrm{n}=404)$ & rs12980275 & 0.068 & 0.061 & $1.09(0.78-1.53)$ & 0.60 & $1.06(0.74-1.51)$ & 0.75 & $2.86(0.35-23.11)$ & 0.32 \\
\hline HCC occurrence & rs8099917 & 0.045 & 0.060 & $0.82(0.52-1.27)$ & 0.37 & $0.86(0.54-1.37)$ & 0.51 & - & - \\
\hline $\operatorname{HCC}(\mathrm{n}=417)$ vs. & rs12979860 & 0.052 & 0.066 & $0.80(0.53-1.23)$ & 0.31 & $0.84(0.54-1.30)$ & 0.43 & - & - \\
\hline $\mathrm{CH}$ and $\mathrm{LC}(\mathrm{n}=618)$ & rs12980275 & 0.053 & 0.077 & $0.72(0.48-1.07)$ & 0.11 & $0.73(0.48-1.13)$ & 0.16 & $0.25(0.03-2.14)$ & 0.20 \\
\hline HCC occurrence on LC & rs8099917 & 0.045 & 0.057 & $0.77(0.47-1.27)$ & 0.31 & $0.84(0.49-1.44)$ & 0.52 & - & - \\
\hline $\mathrm{HCC}(\mathrm{n}=417)$ vs. & rs12979860 & 0.052 & 0.066 & $0.75(0.47-1.19)$ & 0.22 & $0.80(0.48-1.32)$ & 0.38 & - & - \\
\hline $\mathrm{LC}(\mathrm{n}=305)$ & rs12980275 & 0.053 & 0.076 & $0.66(0.43-1.03)$ & 0.07 & $0.69(0.42-1.12)$ & 0.13 & $0.16(0.02-1.40)$ & 0.10 \\
\hline LC occurrence on $\mathrm{CH}$ & rs8099917 & 0.057 & 0.064 & $0.98(0.61-1.58)$ & 0.94 & $0.86(0.51-1.47)$ & 0.59 & $4.93(0.54-44.66)$ & 0.16 \\
\hline $\mathrm{LC}(\mathrm{n}=305) \mathrm{vs}$ & rs12979860 & 0.066 & 0.066 & $1.11(0.70-1.75)$ & 0.66 & $1.01(0.61-1.68)$ & 0.96 & $4.91(0.54-44.52)$ & 0.16 \\
\hline $\mathrm{CH}(\mathrm{n}=313)$ & rs12980275 & 0.076 & 0.077 & $1.08(0.71-1.65)$ & 0.72 & $1.00(0.62-1.61)$ & 1.00 & $2.85(0.53-15.24)$ & 0.22 \\
\hline HBsAg clearance & rs8099917 & 0.041 & 0.050 & $0.78(0.50-1.22)$ & 0.27 & $0.78(0.49-1.24)$ & 0.30 & $0.43(0.03-6.97)$ & 0.56 \\
\hline Chronic $(\mathrm{n}=666)$ vs. & rs12979860 & 0.050 & 0.056 & $0.87(0.57-1.32)$ & 0.51 & $0.88(0.57-1.35)$ & 0.55 & $0.43(0.03-6.85)$ & 0.55 \\
\hline Cleared $(n=353)$ & rs12980275 & 0.056 & 0.061 & $0.91(0.61-1.34)$ & 0.62 & $0.89(0.59-1.34)$ & 0.57 & $1.27(0.13-12.32)$ & 0.84 \\
\hline HBeAg clearance & rs8099917 & 0.057 & 0.034 & $1.64(0.90-2.97)$ & 0.11 & $1.58(0.85-2.94)$ & 0.14 & - & - \\
\hline Chronic $(\mathrm{n}=189)$ vs. & rs12979860 & 0.063 & 0.045 & $1.46(0.84-2.55)$ & 0.18 & $1.41(0.79-2.50)$ & 0.24 & - & - \\
\hline Cleared $(n=428)$ & rs12980275 & 0.069 & 0.051 & $1.33(0.80-2.23)$ & 0.27 & $1.40(0.81-2.42)$ & 0.23 & $0.95(0.08-10.79)$ & 0.97 \\
\hline
\end{tabular}

Minor allele frequencies and $\mathrm{p}$ values for logistic analyses of three alternative models (codominant, dominant and recessive models) are shown.

$\mathrm{SR}=$ Spontaneously recovered.

model; OR $=0.69, \mathrm{p}=0.13$ in a dominant model; OR $=$ $0.16, p=0.10$ in a recessive model) had no statistically significant association with the occurrence of HCC in the LC group.

\section{Effects of Polymorphisms near the IL28B Gene in \\ Other Clinical Fields}

We analyzed the effects of the SNPs near the IL28B gene to $\mathrm{LC}$ occurrence, HBsAg seroconversion and $\mathrm{HBeAg}$ clearance. However, the polymorphisms near the IL28B gene had no significant association with LC occurrence, HBsAg seroconversion or HBeAg seroconversion (table 3).

\section{Discussion}

The purpose of this study was to determine whether polymorphisms near the IL $28 B$ gene could affect natural courses of $\mathrm{HBV}$ infection. Three polymorphisms near the $I L 28 B$ gene were identified and no significant association was identified between these 3 polymorphisms and the natural history of chronic HBV infection including the serologic response and HCC occurrence.
There have been only a few studies regarding associations of SNPs near the IL28B gene with HBV clinical outcomes and the results are somewhat contradictory. Recently, Sonneveld et al. [25] showed that genetic polymorphisms near the IL28B gene, including rs12980275 and rs12979860, are associated with higher rates of serologic response to PEG-IFN in patients with $\mathrm{HBeAg}$ positive $\mathrm{CHB}$. However, the results of studies on the association of SNPs near the IL28B gene with natural courses of chronic HBV infection are inconsistent, as contrasted with chronic HCV infection. Martin et al. [31] reported that the SNP upstream of the IL28B gene rs12979860 was not related to the immune response to HBV. On the contrary, Li et al. [32] described that the three polymorphisms dealt with in our study might affect the HBV clinical outcomes by suppression of viral load and hepatic inflammation among a Chinese Han population. Previous studies support the latter results by showing that IFN- $\lambda$ suppresses HBV viral replication in vivo $[16,22]$.

The current study did not find a significant relationship between genetic variations near the IL28B gene and natural courses of chronic HBV infection. There are 
several advantages that would further strengthen this study compared to previous similar studies, and would add to the reliability of our results. First, our study included a large number of subjects, 1,439 individuals with chronic HBV infection, which is more than twice the subjects included in previous studies. This would further add to the statistical power of analysis and search more SNPs than ever. Second, this study was conducted in a place where almost all patients had their infections transmitted vertically [33]. The mode of transmission is relatively homogenous as contrasted with previous studies, where the impact of the mode of transmission as a potentially confounding factor could be minimized. Considering that the most significant factor affecting the chronicity of HBV infection is age at infection, the chronicity in Korean patients seems to be determined by host factors or genetic differences rather than viral factors such as variations in virulence of the viral strains [34-36]. Third, we included only antiviral-naive subjects; in contrast, the previous similar studies which investigated natural courses of chronic HBV infection did not set any limitation regarding antiviral treatment.

The sustained virological response rates of HCV infection to PEG-IFN and ribavirin are higher in Asian patients compared with other ethnic groups. A previous study showed that Asian race is one of the independent predictors of sustained virological response in a multivariate logistic regression analysis [37]. The sustained virological response rates of Korean patients in particular are about $10 \%$ higher than those of Caucasian [38-40]. The causes of racial variation are still unclear. Some factors, like cytokine production and hepatic iron level, have been considered as the origin of inter-ethnic differences in prior investigations $[41,42]$. Since the strong associations of IL28B gene polymorphisms with $\mathrm{HCV}$ clearance have been demonstrated, SNPs near the IL28B gene are thought to be the leading cause of racial variation of $\mathrm{HCV}$ clinical outcomes [43]. In this study, we have demonstrated the minor allele frequencies of those polymorphisms among the Korean population. The minor allele frequencies of Koreans are rarer than those of Caucasians, African-Americans, Hispanics and some Asians [44, 45]. Although SNPs near the IL28B gene have no association with HBV natural histories, their minor allele frequencies among Koreans might be important in the studies regarding chronic $\mathrm{HCV}$ infection and treatment response of HBV infection.

However, there are some limitations in this study. Disrelation between genetic variations of the IL28B gene and
HBV clinical outcomes does not mean that IFN- $\lambda$ has no role in HBV pathophysiology. It has been already demonstrated that therapeutic responses to PEG-IFN are dependent on the polymorphisms near the IL28B gene in patients with $\mathrm{HBeAg}$-positive $\mathrm{CHB}$ [25]. The polymorphisms near the $I L 28 B$ gene may modify the immune functions of IFN $-\lambda$. In vitro IFN- $\lambda$ functional assays with mutagenesis studies have not been done even in $\mathrm{HCV}$ fields [46]. Therefore, functional studies to evaluate the expression levels of IFN- $\lambda$ and IFN-stimulated genes are needed in CHB patients with or without PEG-IFN treatment. Furthermore, we enrolled only patients with genotype $\mathrm{C}$ [47] and it is therefore unclear whether our findings can be extended to patients with other genotypes. Also, more than $90 \%$ of our cohort had favorable IL $28 B$ polymorphisms and the absence of a statistical relationship might be caused by this deviation. Therefore, the associations of IL28B gene polymorphisms with HBV outcome should be studied in other ethnic cohorts with different viral genotypes.

In conclusion, we have shown the frequencies of minor alleles and haplotypes near the IL28B gene in the Korean population. However, the genetic variations near the IL $28 B$ gene which have strong association with HCV natural history, therapeutic response rates and HBV therapeutic responses have demonstrated no effects on disease progression, $\mathrm{HBeAg}$ clearance and spontaneous recovery in chronic HBV infection.

\section{Acknowledgements}

This study was supported by grants from the SNUH Research Fund (04-2011-023), the Basic Science Research Program (20100009943) and the Basic Research Laboratory program through the National Research Foundation of Korea funded by the Ministry of Education, Science and Technology (2010-0001200). The biospecimens from Ajou University Hospital were provided by the Ajou Human Bio-Resource Bank (AHBB), a member of the National Biobank of Korea, which is supported by the Ministry of Health and Welfare.

References
Shepard CW, Simard EP, Finelli L, Fiore AE Bell BP: Hepatitis B virus infection: epidemiology and vaccination. Epidemiol Rev 2006; 28:112-125.

$\checkmark 2$ Parkin DM: Global cancer statistics in the year 2000. Lancet Oncol 2001;2:533-543.

-3 Siegel R, Ward E, Brawley O, Jemal A: Cancer statistics, 2011: the impact of eliminating socioeconomic and racial disparities on premature cancer deaths. CA Cancer J Clin 2011;61:212-236. 
4 Lin CL, Kao JH: Hepatitis B viral factors and clinical outcomes of chronic hepatitis B. J Biomed Sci 2008;15:137-145.

5 Yu MW, Chang HC, Liaw YF, et al: Familial risk of hepatocellular carcinoma among chronic hepatitis B carriers and their relatives. J Nat Cancer Inst 2000;92:1159-1164.

6 Park BL, Kim YJ, Cheong HS, et al: Association of common promoter polymorphisms of MCP1 with hepatitis B virus clearance. Exp Mol Med 2006;38:694-702.

7 Park TJ, Chun JY, Bae JS, et al: CCND2 polymorphisms associated with clearance of HBV infection. J Hum Genet 2010;55:416420.

$>8$ Chun JY, Bae JS, Park TJ, et al: Putative association of DNA methyltransferase 1 (DNMT1) polymorphisms with clearance of HBV infection. BMB Rep 2009;42:834-839.

9 Park BL, Kim YJ, Cheong HS, et al: HDAC10 promoter polymorphism associated with development of HCC among chronic HBV patients. Biochem Biophys Res Commun 2007; 363:776-781.

10 Jung YJ, Kim YJ, Kim LH, et al: Putative association of Fas and FasL gene polymorphisms with clinical outcomes of hepatitis B virus infection. Intervirology 2007;50:369376.

11 Kim YJ, Kim HY, Kim JS, et al: Putative association of transforming growth factor-alpha polymorphisms with clearance of hepatitis B virus and occurrence of hepatocellular carcinoma in patients with chronic hepatitis B virus infection. J Viral Hepat 2010;17:518526.

$\checkmark 12$ Kim YJ, Lee HS, Im JP, et al: Association of transforming growth factor-betal gene polymorphisms with a hepatocellular carcinoma risk in patients with chronic hepatitis B virus infection. Exp Mol Med 2003;35: 196-202.

$\checkmark 13$ Kim YJ, Yoon JH, Kim CY, et al: IGF2 polymorphisms are associated with hepatitis $\mathrm{B}$ virus clearance and hepatocellular carcinoma. Biochem Biophys Res Commun 2006; 346:38-44.

$\downarrow_{14}$ Shin HD, Park BL, Cheong HS, Yoon JH, Kim YJ, Lee HS: SPP1 polymorphisms associated with HBV clearance and HCC occurrence. Int J Epidemiol 2007;36:1001-1008.

- 15 Marcello T, Grakoui A, Barba-Spaeth G, et al: Interferons alpha and lambda inhibit hepatitis $C$ virus replication with distinct signal transduction and gene regulation kinetics. Gastroenterology 2006;131:1887-1898.

16 Robek MD, Boyd BS, Chisari FV: Lambda interferon inhibits hepatitis $B$ and $C$ virus replication. J Virol 2005;79:3851-3854.

17 Ge D, Fellay J, Thompson AJ, et al: Genetic variation in IL28B predicts hepatitis C treatment-induced viral clearance. Nature 2009, 461:399-401.
18 Thomas DL, Thio CL, Martin MP, et al: Genetic variation in IL28B and spontaneous clearance of hepatitis C virus. Nature 2009; 461:798-801.

19 Li W, Lewis-Antes A, Huang J, Balan M, Kotenko SV: Regulation of apoptosis by type III interferons. Cell Prolif 2008;41:960-979.

20 Numasaki M, Tagawa M, Iwata F, et al: IL-28 elicits antitumor responses against murine fibrosarcoma. J Immunol 2007;178:50865098

21 Maher SG, Sheikh F, Scarzello AJ, et al: IFNalpha and IFNlambda differ in their antiproliferative effects and duration of JAK/STAT signaling activity. Cancer Biol Ther 2008;7:1109-1115.

22 Li M, Liu X, Zhou Y, Su SB: Interferon-lambdas: the modulators of antivirus, antitumor, and immune responses. J Leukoc Biol 2009; 86:23-32.

23 Fabris C, Falleti E, Cussigh A, et al: IL-28B rs12979860 C/T allele distribution in patients with liver cirrhosis: role in the course of chronic viral hepatitis and the development of HCC. J Hepatol 2011;54:716-722.

24 Ank N, West H, Bartholdy C, Eriksson K, Thomsen AR, Paludan SR: Lambda interferon (IFN-lambda), a type III IFN, is induced by viruses and IFNs and displays potent antiviral activity against select virus infections in vivo. J Virol 2006;80:4501-4509.

25 Sonneveld MJ, Wong VW, Woltman AM, et al: Polymorphisms near IL28B and serologic response to peginterferon in $\mathrm{HBeAg}$-positive patients with chronic hepatitis B. Gastroenterology 2012;142:513-520.

26 Bruix J, Sherman M: Management of hepatocellular carcinoma: an update. Hepatology 2011;53:1020-1022.

27 Livak KJ: Allelic discrimination using fluorogenic probes and the $5^{\prime}$ nuclease assay. Genet Anal 1999;14:143-149.

28 Lagging M, Askarieh G, Negro F, et al: Response prediction in chronic hepatitis $\mathrm{C}$ by assessment of IP-10 and IL28B-related single nucleotide polymorphisms. PloS One 2011; 6:e17232.

29 Stephens M, Smith NJ, Donnelly P: A new statistical method for haplotype reconstruction from population data. Am J Hum Genet 2001;68:978-989.

30 Barrett JC, Fry B, Maller J, Daly MJ: Haploview: analysis and visualization of $\mathrm{LD}$ and haplotype maps. Bioinformatics 2005;21: 263-265.

- 31 Martin MP, Qi Y, Goedert JJ, et al: IL28B polymorphism does not determine outcomes of hepatitis B virus or HIV infection. J Infect Dis 2010;202:1749-1753.

32 Li W, Jiang Y, Jin Q, et al: Expression and gene polymorphisms of interleukin $28 \mathrm{~B}$ and hepatitis B virus infection in a Chinese Han population. Liver Int 2011;31:1118-1126.

33 Kwon SY, Lee CH: Epidemiology and prevention of hepatitis B virus infection. Korean J Hepatol 2011;17:87-95.
34 Stevens CE, Beasley RP, Tsui J, Lee WC: Vertical transmission of hepatitis B antigen in Taiwan. N Engl J Med 1975;292:771-774.

35 Coursaget P, Yvonnet B, Chotard J, et al: Ageand sex-related study of hepatitis B virus chronic carrier state in infants from an endemic area (Senegal). J Med Virol 1987;22: $1-5$.

36 Tassopoulos NC, Papaevangelou GJ, Sjogren $\mathrm{MH}$, Roumeliotou-Karayannis A, Gerin JL, Purcell RH: Natural history of acute hepatitis B surface antigen-positive hepatitis in Greek adults. Gastroenterology 1987;92: 1844-1850.

37 Missiha S, Heathcote J, Arenovich T, Khan $\mathrm{K}$ : Impact of Asian race on response to combination therapy with peginterferon alfa-2a and ribavirin in chronic hepatitis C. Am J Gastroenterol 2007;102:2181-2188.

- 38 Fried MW, Shiffman ML, Reddy KR, et al: Peginterferon alfa-2a plus ribavirin for chronic hepatitis $\mathrm{C}$ virus infection. $\mathrm{N}$ Engl J Med 2002;347:975-982.

39 Kwon JH, Bae SH, Choi JY, et al: Assessment of the efficacy of reducing peginterferon alpha-2a and ribavirin dose on virologic response in Koreans with chronic hepatitis C. Korean J Intern Med 2009;24:203-211.

40 Jeong SW, Kim JD, Woo HY, et al: Impact of adherence to peginterferon-ribavirin combination therapy in chronic hepatitis $\mathrm{C}$ patients on achieving a sustained virologic response. Korean J Hepatol 2009;15:338-349.

41 Ioannou GN, Dominitz JA, Weiss NS, Heagerty PJ, Kowdley KV: Racial differences in the relationship between hepatitis $\mathrm{C}$ infection and iron stores. Hepatology 2003;37: 795-801.

42 Kimball P, Elswick RK, Shiffman M: Ethnicity and cytokine production gauge response of patients with hepatitis $C$ to interferon-alpha therapy. J Med Virol 2001;65:510-516.

43 Clark PJ, Thompson AJ, McHutchison JG: IL28B genomic-based treatment paradigms for patients with chronic hepatitis $\mathrm{C}$ infection: the future of personalized HCV therapies. Am J Gastroenterol 2011;106:38-45.

$\checkmark 44$ Lyoo K, Song MJ, Hur W, et al: Polymorphism near the IL28B gene in Korean hepatitis $C$ virus-infected patients treated with peg-interferon plus ribavirin. J Clin Virol 2011;52:363-366.

45 Bochud PY, Bibert S, Negro F, et al: IL28B polymorphisms predict reduction of HCV RNA from the first day of therapy in chronic hepatitis C. J Hepatol 2011;55:980-988.

46 Kelly C, Klenerman P, Barnes E: Interferon lambdas: the next cytokine storm. Gut 2011; 60:1284-1293.

47 Song BC, Cui XJ, Kim H: Hepatitis B virus genotypes in Korea: an endemic area of hepatitis B virus infection. Intervirology 2005; 48:133-137.

Lee et al. 